\title{
Lidar depolarization measurement of fresh volcanic ash from Mt. Etna, Italy
}

\author{
Gianluca Pisani ${ }^{\mathrm{a}, *}$, Antonella Boselli ${ }^{\mathrm{b}}$, Mauro Coltelli ${ }^{\mathrm{c}}$, Giuseppe Leto ${ }^{\mathrm{d}}$, Giulia Pica ${ }^{\mathrm{e}}$, Simona Scollo $^{\mathrm{c}}$, \\ Nicola Spinelli ${ }^{a}$, Xuan Wang ${ }^{\text {a,f }}$ \\ ${ }^{a}$ CNISM and Dipartimento di Scienze Fisiche - Università di Napoli "Federico II", 80126 Napoli, Italy \\ ${ }^{\mathrm{b}}$ CNISM and IMAA-CNR, 85050 Tito Scalo, Potenza, Italy \\ ${ }^{\mathrm{c}}$ Istituto Nazionale di Geofisica e Vulcanologia, Osservatorio Etneo, 95123 Catania, Italy \\ d INAF, Osservatorio Astrofisico di Catania, 95123 Catania, Italy \\ e CO.RI.S.T.A, 80126 Napoli, Italy \\ ${ }^{\mathrm{f}}$ SPIN-CNR and Dipartimento di Scienze Fisiche - Università di Napoli "Federico II" - 80126 Napoli, Italy
}

\section{H I G H L I G H T S}

- Ash emission from Mt Etna was followed by a polarization lidar.

- Particle depolarization of fresh volcanic ash was measured near the source.

- Depolarization and lidar ratio values of two plumes components were determined.

- Estimation of volcanic ash mass concentration at source was performed.

\section{A R T I C L E I N F O}

\section{Article history:}

Received 29 April 2012

Received in revised form

3 August 2012

Accepted 8 August 2012

\section{Keywords:}

Lidar

Volcanic ash

Mass concentration

Depolarization

Lidar-ratio

\begin{abstract}
A B S T R A C T
A small, portable, polarization lidar system with scanning capability was used to perform range resolved measurements of fresh erupted volcanic plume from Mount Etna in Italy. Measurements were carried out on November 15, 2010 during a volcanic plume emission event by placing the lidar very close to volcano summit craters. Depolarization measurements highlighted that aerosol of different shape and optical properties were emitted by the two involved vents, Bocca Nuova and North-East Craters. In the plume emitted from Bocca Nuova Crater the mean value of aerosol linear depolarization ratio resulted near to zero, corresponding to non depolarizing particles or liquid droplets, while values of $(16 \pm 2) \%$ and $(45 \pm 3) \%$ were observed in the ash plume emitted from North-East Crater, in the morning and in the afternoon, respectively. The retrieved values of volcanic aerosol depolarization ratio, aerosol backscattering and lidar-ratio allowed distinguishing the changes in the properties of the emitted aerosol. Furthermore, the ash mass concentration at source was estimated, reaching a maximum value of $24,000 \pm 6000 \mu \mathrm{g} \mathrm{m}^{-3}$, with an additional systematic uncertainty of $50 \%$ related to the assumption of an effective radius of $10 \mu \mathrm{m}$ for ash particles.
\end{abstract}

(c) 2012 Elsevier Ltd. All rights reserved.

\section{Introduction}

The aerosol produced during volcanic activities has a huge impact on the global environment. In fact, major eruptions strongly influence the Earth's radiative balance by injecting in the atmosphere a great amount of particles and gases which produce secondary aerosols (Mather et al., 2003).

The interest in the study of volcanic ash plumes comes also from their large dispersion scale and long residence times, since these

\footnotetext{
* Corresponding author.

E-mail address: pisani@na.infn.it (G. Pisani).
}

ashes represent a serious hazard to aircraft engines. Recently, the Eyjafjallajokull volcano eruption in Iceland (March 20, 2010) raised this problem, demonstrating the high vulnerability of the human flight transport system. During this eruption, near-real time observations of the volcanic cloud evolution were performed by groundbased lidar stations of EARLINET network (Ansmann et al., 2010; Gasteiger et al., 2011), demonstrating the ability of lidar networks to detect and monitor the evolution of volcanic aerosol plumes.

During the last years, lidar systems were widely used to study volcanic aerosol clouds produced by major volcanic eruptions (Chazette et al., 1995; Langford et al., 1995; Di Girolamo et al., 1996; Ansmann et al., 2010). In particular, the polarization lidar technique was used to distinguish the shape and thermodynamic phase of 
atmospheric aerosol (Winker and Osborn, 1992; Sassen, 2005; Sassen et al., 2007). Moreover, the possibility to discriminate volcanic ash from desert dust could have a strong influence on airtraffic decision management. This is of particular relevance in the countries of Southern Europe and specially in Italy, which is frequently affected by volcanic ash emissions from three active volcanoes (Etna, Stromboli and Vulcano) (Edner et al., 1994; Pappalardo et al., 2004; Wang et al., 2008a,b; Fiorani et al., 2009), and by Saharan dust transport events (Mona et al., 2006; Papayannis et al., 2008). Data on volcanic aerosol may also be useful in transport and climatological models applications. In this context, aerosol linear depolarization ratio and lidar-ratio directly measured at source represent reference values for lidar monitoring of volcanic emissions. At the best of our knowledge, the lidar measurements reported in the present paper represent the first attempt to perform these measurements directly on volcanic plume as emitted. The obtained results demonstrate that lidar measurements of these quantities allow real time monitoring of changes of volcanic aerosol optical properties.

In this paper we report on aerosol linear depolarization ratio lidar measurements of volcanic emissions performed at Mt. Etna (Italy), close to summit craters. A small portable lidar system (VAMP - Volcanic Ash Monitoring by Polarization), described in detail in Section 2, was intercalibrated with the Napoli Earlinet lidar station (MALIA - Multi-wavelength Aerosol LIdar Apparatus), and installed about $7 \mathrm{~km}$ far from Etna summit craters. The intercalibration procedure and the iterative approach used to estimate the mean lidar-ratio in the emitted plume are discussed in the methodology (Section 3). The analysis of the volcanic aerosol emission of November 15, 2010 is presented in Section 4. The estimated mean lidar-ratio, the aerosol backscatter coefficient and the aerosol linear depolarization ratio values allowing to characterize the volcanic emission are also reported. Indeed, the aerosol linear depolarization ratio and backscatter coefficients were used to estimate the mass concentration of fresh emitted ash just above craters. Conclusions are reported in Section 5.

\section{Measurement system}

The VAMP system is a portable lidar with scanning capabilities. It is equipped with a Nd:YAG laser source with repetition rate of $1 \mathrm{kHz}$. The $532 \mathrm{~nm}$ laser pulses are emitted with an energy of $0.3 \mathrm{~mJ}$, a duration of $40 \mathrm{nsec}$ and a linear polarization better than $100: 1$. The beam divergence is reduced to less than $0.1 \mathrm{mrad}$ FWHM by a five time beam expander. The lidar operates in biaxial configuration. The receiver is a Cassegrain telescope with a $20 \mathrm{~cm}$ aperture diameter, a focal length of $140 \mathrm{~cm}$, and a field of view of 1 mrad. An interferential filter (CWL $532 \mathrm{~nm}$, FWHM $0.5 \mathrm{~nm}$ ) is used for spectral selection. A thin film plate polarizing beamsplitter (extinction ratio better than 500:1) separates the components of the backscatter radiation, parallel (P) and cross-polarized $(\mathrm{S})$ with respect to the polarization plane of the emitted laser beam. Two different channels are used detect the two components. The cross-talk coefficients between the two polarization channels were measured resulting lower than $3 \%$ and $0.2 \%$ for the P and S channel, respectively. The whole lidar system is mounted on a motorized fork, allowing a scanning speed of $0.1 \operatorname{rad~s}^{-1}$. The actual scanning speed is limited by the signal to noise ratio of the registered profile. During night-time measurements, single lidar profiles extend up to $20 \mathrm{~km}$ with a temporal integration of less than $20 \mathrm{~s}$. In day-time conditions $1 \mathrm{~min}$ of time integration is required in order to have backscattering and aerosol linear depolarization ratio profiles extending up to $10 \mathrm{~km}$.

Lidar data were acquired in photon counting mode, and signals were stored with a raw spatial resolution of $30 \mathrm{~m}$. To increase the signal to noise ratio the final spatial resolution is reduced to $60 \mathrm{~m}$ for backscattering calculation. The actual resolution of aerosol linear depolarization ratio profiles was set at $60 \mathrm{~m}$ in the plume regions, while it was $180 \mathrm{~m}$ or $300 \mathrm{~m}$ below the layer base and $420 \mathrm{~m}$ above the volcanic plume, respectively.

\section{Method}

The VAMP lidar allows one to detect only elastic back-scattered radiation at $532 \mathrm{~nm}$, hence the knowledge of the extinction-tobackscattering ratio, also known as lidar-ratio (LR), is required in order to obtain the backscatter coefficient profile. The most recent estimations of LR for volcanic aerosol were performed in 2010, during the eruption of the Eyjafjallajokull volcano. Raman lidar measurements carried out during this event provided $532 \mathrm{~nm}-\mathrm{LR}$ values for volcanic aerosol after a long range transport in the range from $50 \mathrm{sr}$ to $60 \mathrm{sr}$ and from $50 \mathrm{sr}$ to $90 \mathrm{sr}$ in Germany (Ansmann et al., 2011; Wiegner et al., in press) and in Italy (Mona et al., 2012), respectively. Furthermore, lidar measurements at $355 \mathrm{~nm}$ performed at Exeter (UK) showed values of LR around $80 \mathrm{sr}$ (Marenco and Hogan, 2011). Nevertheless, measurements of LR of just erupted volcanic aerosol are not yet available.

In the present work the mean value of the LR in the volcanic plume was estimated through an iterative procedure. This procedure requires the evaluation of the optical depth (OD) of the volcanic plume. OD can be determined by comparing the measured lidar signal with the reference molecular profile in two regions located before and behind the plume, respectively, where the aerosol load can be assumed negligible (Di Girolamo et al., 1995). the optical depth of the plume was directly evaluated as $\mathrm{OD}=0.5 \ln \left(\gamma_{b} / \gamma_{a}\right), \gamma_{b}$ and $\gamma_{a}$ being the normalizing factors between the measured lidar signal and molecular profile from the atmospheric standard models, estimated in the two regions where the aerosol load can be assumed negligible. The values of the determined OD are affected by statistical and systematic errors. The former takes into account the signal errors. The systematic error associated to the assumption of molecular conditions in the two selected regions takes into account background aerosol load. Its contribution has been evaluated considering that measurement were performed in clear sky and no aerosol outbreak conditions, so that in the interested altitude the aerosol backscatter is less than $\sim 10^{-7} \mathrm{sr}^{-1} \mathrm{~m}^{-1}$ (as evaluated by Sicard et al., 2011, for Mediterranean region), while in the plume we measured values more than 2 order of magnitude higher (see below). Another systematic contribution of $2-3 \%$ is due to the accuracy of the atmospheric model (Di Girolamo et al., 1995).

In these conditions, the iteration starts from a first guess of the mean value of $\operatorname{LR}\left(\operatorname{LR}_{0}=50 \mathrm{sr}\right)$ in the volcanic plume and the aerosol backscatter coefficient profile is obtained trough the Klett-Fernald analytical algorithm (Fernald, 1984; Klett, 1985). A new mean value of the $L R\left(L_{1}\right)$ is evaluated from the ratio between the above estimated value of OD and the integrated value of the aerosol backscatter coefficient in the plume. The value $L_{1}$ is then used for a new iteration. This procedure converges after a few iterations. A change of a factor 2 of the first guess value brings no appreciable changes in the results for the mean value of LR in the plume.

The presence of the two above mentioned aerosol-free regions (before and behind the volcanic plume) allowed us to check the reliability of the solution for LR. Actually, a different procedure was also followed to determine the LR mean value of the plume, by evaluating the backscattering profile with the constraint of null value of the aerosol backscatter coefficient in the two aerosol-free regions. These two different approaches allowed us to estimate the errors on LR mean value as deviation of the two results; they resulted lower than $20 \%$ in all cases. Therefore, this deviation has 
been considered as the error of the LR value in the subsequent analysis.

Error calculations regarding the Klett-inversion were recently treated by Rocadenbosch et al. (2010). In our analysis, the uncertainty affecting the aerosol backscatter coefficient at range $z$ was evaluated by taking into account four contributions: i) the error on the LR choice; ii) the error on the signal at $z$; iii) the error on the signal at reference range $\left(z_{0}\right)$; iv) the error on the aerosol backscatter value at $z_{0}$. The statistical error on signals acquired with the VAMP system is a function of the distance of the sounded atmospheric volume, and of data binning on time and space. For daytime acquisitions, at a distance of about $7 \mathrm{~km}$, we found that the statistical error on $1 \mathrm{~min}$ integrated total elastic signal, with a spatial resolution of $30 \mathrm{~m}$, was of the order of $10 \%$ and $30 \%$ for the $P$ and $S$ components, respectively. The above evaluation was carried out in clear sky conditions. Moreover, in the presence of plume (at about $7 \mathrm{~km}$ ), the high levels of both $\mathrm{P}$ and $\mathrm{S}$ signals lead to corresponding statistical errors of about $5 \%$, and $10 \%$, respectively, for an integration time of $60 \mathrm{~s}$, and $30 \mathrm{~m}$ spatial resolution. In nighttime conditions, and with a $20 \mathrm{~s}$ integration time and $30 \mathrm{~m}$ spatial resolution, the statistical errors were of the order of $5 \%$ for both $\mathrm{P}$ and $\mathrm{S}$ channels in the volcanic plume.

A constant value of $45 \mathrm{sr}$ was assumed for the LR of the atmospheric region free from volcanic plume, as derived for the Mediterranean region from Sicard et al. (2011); by varying this value by $\pm 50 \%$, we observed a variation of the integrated value of the plume aerosol backscatter coefficient of less than $2 \%$.

The reference point is chosen within a range $(>0.5 \mathrm{~km})$ where the lidar signal can be fitted with a pure molecular profile so that the aerosol scattering at this point is negligible with respect to Rayleigh scattering, and the fitting pure molecular profile at $z_{0}$ is considered instead of the elastic signal in the inversion algorithm. With this method the error on the backscattering profiles linked to the choice of the reference point depends, in practice, only on the atmospheric model accuracy, and can be kept as low as of $2-3 \%$ (Di Girolamo et al., 1995).

The calibrated power ratio between the light components detected in $\mathrm{P}$ and $\mathrm{S}$ channels is known as the linear volume depolarization ratio, $\delta_{V}$. A very general expression of measured backscatter components $\beta_{P}^{m}$ and $\beta_{S}^{m}$, which takes into account the polarization degree of the laser source $(\alpha)$ and cross talking of two channels ( $B^{\|}$and $B^{\perp}$ ) was reported by Biele et al. (2000) as:

$\beta_{P}^{m}=\frac{\beta_{T}}{2}\left[1+\frac{1-\delta_{V}}{1+\delta_{V}}(1-\alpha)\left(1-B^{\|}\right)\right]$

$\beta_{S}^{m}=\frac{\beta_{T}}{2}\left[1-\frac{1-\delta_{V}}{1+\delta_{V}}(1-\alpha)\left(1-B^{\perp}\right)\right]$

where $\beta_{P}$ and $\beta_{S}$ are the parallel and perpendicular backscatter coefficients, respectively and $\beta_{T}=\beta_{P}+\beta_{S}$. For our equipment $\left(1-B^{\|}\right) \approx\left(1-B^{\perp}\right) \approx 1$, therefore the contribution of non perfect polarization of the laser beam is the dominant effect.

By expressing $\alpha$ in terms of the ratio $k=I_{S} / I_{P}$ between the components of the laser line, we obtain $\alpha=2 k /(1+k)$ and the $\delta_{V}$ can be written as:

$\delta_{V}=\frac{\beta_{S}(z)}{\beta_{P}(z)}=\left(H \frac{S(z)}{P(z)}-k\right)\left(1-k H \frac{S(z)}{P(z)}\right)^{-1}$

where $H$ (gain ratio) is the calibration constant, which takes into account the different efficiencies of the detection channels for power measured by the parallel, $P(z)$, and perpendicular, $S(z)$, polarization channels, and $k$ takes into account the linear polarization degree of laser beam and the angular misalignment of the receiving optics.

Once the scattering ratio $R=\left(\beta_{\mathrm{aer}}+\beta_{\mathrm{mol}}\right) / \beta_{\mathrm{mol}}$ is known, the aerosol linear depolarization ratio, $\delta_{\text {aer }}$, can be determined as:

$\delta_{\mathrm{aer}}=\frac{\left(1+\delta_{\mathrm{mol}}\right) \delta_{V} R-\left(1+\delta_{V}\right) \delta_{\mathrm{mol}}}{\left(1+\delta_{\mathrm{mol}}\right) R-\left(1+\delta_{V}\right)}$

where $\delta_{\mathrm{mol}}$ is the molecular linear depolarization, which depends on the interferential filter bandwidth and the field of view of the receiving channel. In our case $\delta_{\text {mol }}$ assumes the value of $0.37 \%$ (Behrendt and Nakamura, 2002).

In order to determine the coefficients $H$ and $k$ of the VAMP system, intercomparison measurements (at $532 \mathrm{~nm}$ ) were performed with the EARLINET polarization lidar system MALIA (Wang et al., 2008a,b) located in Napoli $\left(14.2^{\circ} \mathrm{E}, 40.8^{\circ} \mathrm{N}\right)$. MALIA is periodically calibrated for depolarization measurements at $532 \mathrm{~nm}$ through the technique proposed by Freudenthaler et al. (2009). This method consists in performing two measurements by rotating the direction of the laser linear polarization by $45^{\circ}$ in two opposite directions, while simultaneously recording the $\mathrm{P}$ and $\mathrm{S}$ signals. This procedure shows low sensitivity to the atmospheric instabilities, and allows the calibration at every altitude.

Intercomparison measurements were performed in June-July 2010. The coefficients $H$ and $k$ for VAMP were determined by minimizing the quantity:

$\sum_{z} \frac{\left(\delta_{V, M}-\delta_{V, V}\right)^{2}}{\sigma_{M}^{2}+\sigma_{V}^{2}}$

where $\delta_{V, M}$ and $\delta_{V, V}$ represent the volume linear depolarization ratios obtained from MALIA and VAMP (whose interferential filters had the same bandwidth), respectively, and $\sigma_{M}$ and $\sigma_{V}$ are their errors. The error $\sigma_{M}$ takes into account the errors on signals and on calibrations constants. The error $\sigma_{V}$ is calculated from propagation of errors on $S(z)$ and $P(z)$ through Eq. (2), and assigning to $H$ and $k$ the values derived by a first minimization of the quantity (4), with $\sigma_{V}=0$. The sum is then calculated over the full range sounded by the two lidars.

The results of Fig. 1 refer to the intercomparison measurements carried out on June 9, 2010. Fig. 1(a) shows two $\delta_{V}$ profiles, while the

Napoli June 9, 2010 - 19:00-19:30GMT
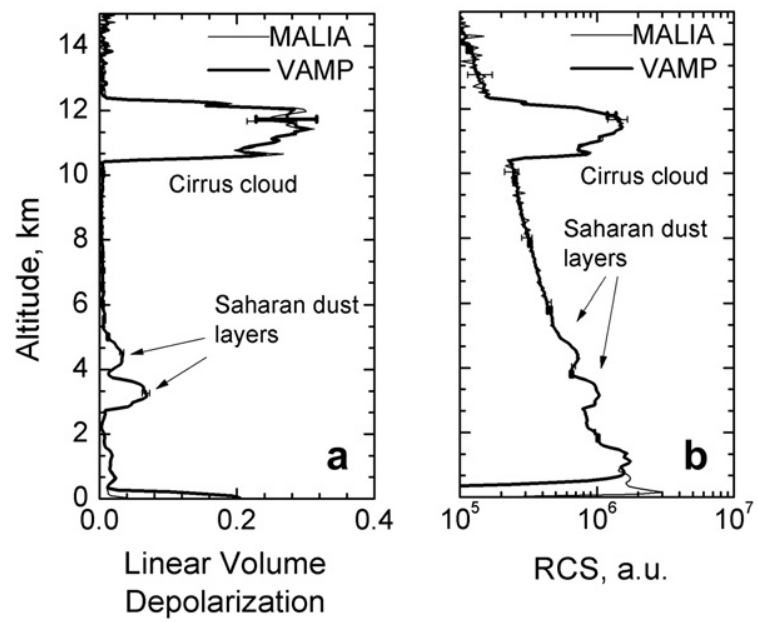

Fig. 1. Volume linear depolarization (a) and total RCS (b) at $532 \mathrm{~nm}$ from VAMP and MALIA lidars. Data were acquired pointing to the vertical direction with a spatial resolution of $60 \mathrm{~m}$ and an integration time of $1800 \mathrm{~s}$, starting at 19:00 GMT. 
corresponding total range corrected signals (RCS) are reported in Fig. 1(b). In Fig. 1, the layers between 3 and $6 \mathrm{~km}$ above the lidar station correspond to Saharan dust, as shown from backtrajectories by HYSPLIT Model (Draxler and Rolph, 2012; Rolph, 2012), while a cirrus cloud was observed above $10 \mathrm{~km}$ of altitude. The discrepancies below $1 \mathrm{~km}$ are due to differences in the overlap functions of the two lidars.

To test the stability of the system, the intercomparison procedure was performed several times in day and night time conditions, with the presence of cirrus or Saharan dust layers. A confirmation of the system stability came from the comparison with results of the molecular calibration procedure (Behrendt and Nakamura, 2002), systematically performed whenever possible.

Mean values of $0.072 \pm 0.005$ and $0.01 \pm 0.01$ were obtained for $\mathrm{H}$ and $k$ of the VAMP lidar, respectively; the errors on $\mathrm{H}$ and $k$ take into account standard deviations and the systematic error due to the uncertainty on the MALIA system calibration constant, which is of the order of $2 \%$, as determined from a long series of calibration procedures.

The errors on $\delta_{V}$ were evaluated by propagating the errors on the gain ratio $H$, the calibration constant $K$, and the statistical errors of the two signals through Eq. (2). The error on $\delta_{\mathrm{mol}}$ is a function of the transmission curve of the interferential filter and of the temperature of the atmosphere in the sounded range. Actually, the temperature of the volcanic aerosol during the emission event on November 15, 2010 may be assumed close to air temperature. In fact, no sustained eruption column was present, and volcanic aerosol reached quickly the thermal equilibrium with the environment. This was confirmed by the surveillance IR cameras located close the volcanic vent. Therefore, an overall error of $5 \%$ on $\delta_{\text {mol }}$ is assumed (Behrendt and Nakamura, 2002). The uncertainties on $\delta_{\text {aer }}$ were derived by propagating the above discussed errors through Eq. (3).

Multiple scattering (MS) is often observed within layers consisting of high depolarizing aerosol, as, e.g., like ice crystals in cirrus clouds (Bissonnette, 2005). In order to avoid misinterpretation in depolarization measurement results, an evaluation of the influence of MS in our measurements was done by plotting the mean $\delta_{V}$ versus the OD estimated in our volcanic aerosol measurement campaign. As Fig. 2 shows, $\delta_{V}$ measured between 0.1 and $0.5 \mathrm{OD}$ for the two different plumes brings us to the consideration that in the plume formed by non-ash particles the maximum contribution of the MS can be evaluated at $\sim 2-3 \%$, while for the ash plume it is approximately $5 \%$. This is mainly due to the high depolarization nature of the volcanic ash, and their

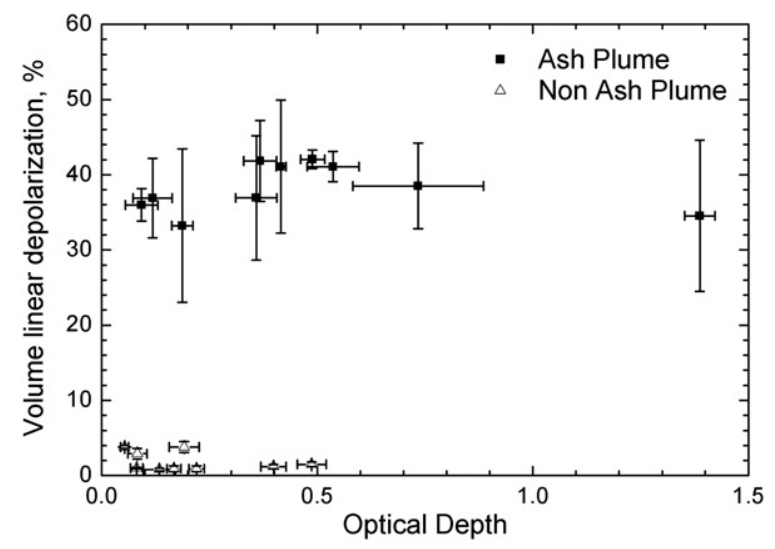

Fig. 2. Scatter plot of volume linear depolarization versus estimated optical depth of the plume from NEC. Error bars represent the standard deviations on $\delta_{V}$ and OD. Data refers to ash emission of November 15, 2010. relative short distance from lidar system. As further caution, in this paper we have considered only measurements corresponding to OD lower than 0.5 in the volcanic plume in order to avoid any possible MS influence.

\section{Analysis of volcanic aerosol emission of November 15, 2010}

After the intercomparison, the VAMP system was placed at Serra della Nave Astronomical Observatory $\left(14.97^{\circ} \mathrm{E}, 37.69^{\circ} \mathrm{N}\right)$ of the INAF (National Institute for Astrophysics), located at $1760 \mathrm{~m}$ above sea level (a.s.l.) on the S-SW slope of the Mt. Etna volcano, about $7 \mathrm{~km}$ from summit craters (Fig. 3).

The volcanic activity started at 06:40 GMT of November 14, 2010, involving Bocca Nuova Crater (BNC) and the North East Crater (NEC), which produced several volcanic aerosol emission events. Lidar measurements were performed between 12:30 and 17:30 GMT of November 15. During field surveys of volcanologists on duty, high degassing was continuously observed from the BNC (Behncke et al., 2010). The performed measurements are reported in the text following the timing with which they were carried out.

As shown in Fig. 3, the plumes from the two active craters were approximately in the same line-of-view from the lidar site. Therefore, they could not be scanned separately, and appear at different time ranges in the same lidar signals (see Fig. 4). During the daytime measurements (12:38-13:29 GMT), the plumes from the BNC and NEC showed some degree of mixing, hence, for these measurements, we only had the possibility to retrieve the mean value of aerosol LR for the overall plume. The estimated mean values of the LR for 10 lidar profiles varied between $30 \mathrm{sr}$ and $45 \mathrm{sr}$. These values of lidar-ratio are smaller compared to those reported by several lidar stations in the recent volcanic plume outbreaks (e. g., Ansmann et al., 2011; Miffre et al., 2011; Gro $\beta$ et al., 2012) for aged volcanic aerosol. Even though the backscattering profiles did not show well separated layers, a clear difference in the $\delta_{\text {aer }}$ profile was observed.

An example of the aerosol backscattering and aerosol linear depolarization profiles acquired in day-time condition with an integration time of $60 \mathrm{~s}$ is shown in Fig. 4(a). Applying the Klett

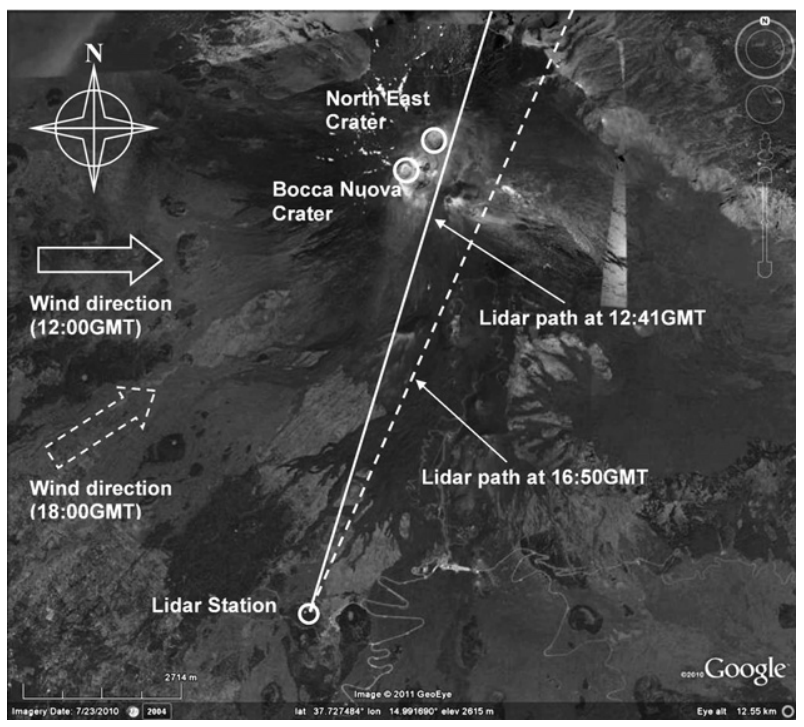

Fig. 3. Illustration of the measurement field. The Lidar station of INAF Serra della Nave Astronomical Observatory is located at $1760 \mathrm{~m}$ a.s.l. $\left(14.97^{\circ} \mathrm{E}, 37.69^{\circ} \mathrm{N}\right)$. Bocca Nuova Crater (BNC) and North East Crater (NEC) are shown. Lidar pointing directions are also reported together with the corresponding wind direction at about $4600 \mathrm{~m}$ a.s.l. (Google Earth). 


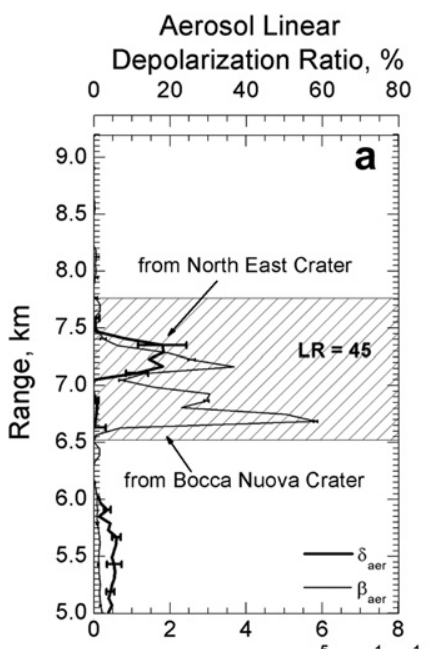

Backscattering $\times 10^{-5}, \mathrm{~m}^{-1} \mathrm{sr}^{-1}$ Backscattering $\times 10^{-5}, \mathrm{~m}^{-1} \mathrm{sr}^{-1}$

Fig. 4. Aerosol backscattering and linear depolarization profiles measured at Serra della Nave - Mt. Etna, November 15, 2010. (a) Data were acquired at an elevation angle of $14^{\circ}$ (corresponding to $250-300 \mathrm{~m}$ of altitude above Mt Etna top) and at $17^{\circ}$ of azimuth angle (clockwise with respect to North direction) and. Integration time was $60 \mathrm{~s}$, starting at 12:41 GMT. (b) Data were acquired at $24^{\circ}$ of azimuth angle (clockwise with respect to North direction) and corresponding at $250-300 \mathrm{~m}$ of altitude above Mt Etna top. The integration time was $20 \mathrm{~s}$, starting at 16:50 GMT, corresponding to night-time conditions.

algorithm for backscattering retrieval, LR values of $60 \mathrm{sr}$ and $30 \mathrm{sr}$ were used in the ranges $4.5-6.2 \mathrm{~km}$ and $6.2-7.5 \mathrm{~km}$, respectively. In the layer between 4.5 and $6.2 \mathrm{~km}$, the mean value of $\delta_{\text {aer }}$ was $(5 \pm 1) \%$, due to background, mixed-aerosol, while the backscatter coefficient value was of the order of $4 \cdot 10^{-7} \mathrm{sr}^{-1} \mathrm{~m}^{-1}$.

During these measurements the mean value of $\delta_{\text {aer }}$ was $<1 \%$ between 6.6 and $7 \mathrm{~km}$ (in the plume from the BNC), and (16 \pm 2$) \%$ beyond $7 \mathrm{~km}$ (in the plume from the NEC), respectively These results suggest that depolarizing ashes were mainly localized between 7 and $7.5 \mathrm{~km}$ from lidar station, in the plume from NEC. Although it is known that the Mt. Etna summit craters are joined in the deeper part of the conduit (e.g. Chester et al., 1985), these craters may show different eruptive styles (e.g. Branca and Del Carlo, 2005) Hence, volcanic aerosols coming out from such craters may present differences in the optical features.

Lidar profiles were acquired also after sunset (from 16:35 to 16:52 GMT). An example of the aerosol backscatter and aerosol linear depolarization profiles recorded in the evening is reported in Fig. 4(b). The plumes appear at longer distance from the lidar station with respect to the day-time measurements, due to a change in the wind direction and a different pointing angle (see also Fig. 3). The mean value of $\delta_{\mathrm{aer}}$ in the plume was ( $\left.5 \pm 2\right) \%$ for the $\mathrm{BNC}$, larger than that observed in the morning for the same plume. Moreover, an increase of the $\delta_{\text {aer }}$ mean value up to $(45 \pm 3) \%$ was observed in the plume from NEC. By averaging the LR values corresponding to fifteen 20-s measurements, we estimated the mean LR for the two plumes. We found LR values of $46 \pm 10 \mathrm{sr}$ and $36 \pm 5$ sr for BNC and NEC, respectively. These observations clearly indicate a change in the type of the emitted volcanic aerosol in both plumes with respect to the day-time case.

The higher value of LR in the BNC plume with respect to that of NEC can be explained by the presence of fine aerosol as, e.g., sulfate particles. These particles are produced by the typical gases emitted from volcanoes (Oppenheimer, 2003), and were also observed in the Eyjafjallajokull plume (Ansmann et al., 2011; Mona et al., 2012).

The contribution of depolarizing and non-depolarizing aerosol to the depolarization ratio in the Eyjafjallajokull volcanic cloud over Lyon (France) was recently studied from Miffre et al. (2011) by means of the scattering matrix method. They found a maximum value of $38.5 \%$ for $\delta_{\text {aer }}$ (at $355 \mathrm{~nm}$ ) also deducing the numerical concentration of ashes. Marenco and Hogan (2011) performed also $355 \mathrm{~nm}$-lidar depolarization measurements finding a mean value of $34 \%$ for the same outbreak event. Compatible values of aerosol depolarization for ashes were also observed by Gro $\beta$ et al. (2012) who found it varying between $35 \%$ and $38 \%$ at $532 \mathrm{~nm}$. Assuming that the plumes emitted by the two Mt. Etna craters were composed by different concentrations of depolarizing (ash) and non depolarizing (non ash) aerosol, we retrieved the ash-related backscatter coefficient, $\beta_{a}$, from the simultaneous evaluation of the $\beta_{\text {aer }}$ and $\delta_{\text {aer }}$ by following the method proposed by Tesche et al. (2009). This method is based on the relation:

$\beta_{a}=\beta_{\mathrm{aer}} \frac{\left(\delta_{\mathrm{aer}}-\delta_{\mathrm{na}}\right)\left(1+\delta_{a}\right)}{\left(\delta_{a}-\delta_{\mathrm{na}}\right)\left(1+\delta_{\mathrm{aer}}\right)}$

where $\delta_{a}$ and $\delta_{\text {na }}$ are the depolarization ratio coefficients of the depolarizing ash and of the weakly depolarizing non-ash aerosol, respectively. Ansmann et al. (2011) used Eq. (5) to separate the contribution of coarse volcanic ash from non-ash aerosol in the total particle backscattering, by assuming a value of $36 \%$ for $\delta_{a}$ and $1 \%$ for $\delta_{\text {na. }}$. In our evening measurements, $\delta_{\text {aer }}$ inside the plume varied between $2 \%$ and $7 \%$ for BNC, and between $10 \%$ and $50 \%$, for NEC. In our calculation we used a value of $(50 \pm 2) \%$ for $\delta_{a}$, corresponding to the maximum value of $\delta_{\text {aer }}$ measured in the ash plume, with the assumption that this value corresponds to a negligible contribution of non-ash aerosol, and the same value used by Ansmann et al. (2011) for $\delta_{\text {na }}$, namely $(1 \pm 1) \%$.

Once $\beta_{a}$ is known, the particle mass concentration of volcanic ash at emitting craters can be obtained by:

$c=\sigma \cdot \beta_{a} \cdot \mathrm{LR} \cdot \rho$

where LR is the measured mean value of the ash lidar-ratio, namely $36 \pm 5 \mathrm{sr}$, and $\rho$ the ash density, set to $2450 \pm 50 \mathrm{~kg} \mathrm{~m}^{-3}$, as found by Scollo et al. (2005) by measuring ash particles erupted in 20022003 from Etna volcano, and for particle size between 0.125 and $0.006 \mathrm{~mm}$. The density of particles having a diameter $<0.008 \mathrm{~mm}$ may be considered equal to the value for lithics $\left(2300-2700 \mathrm{~kg} \mathrm{~m}^{-3}\right)$ (Bonadonna and Phillips, 2003), which is very similar to the value measured from Scollo et al. (2005). In the Eq. (6) $\sigma$ is the ash conversion factor, which is a function of the size distribution, and, for

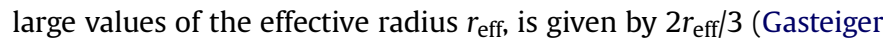
et al., 2011; Schumann et al., 2011). For the volcanic ash cloud observed in Germany 50-110 h after the Eyjafjallajokull eruption, Ansmann et al. (2011) assumed a value of $0.6 \cdot 10^{-6} \mathrm{~m}$ for the conversion factor, corresponding to an effective radius of $1 \mu \mathrm{m}$. This assumption was based on Schumann et al. (2011) findings about the removal by sedimentation of particles with radii $>15 \mu \mathrm{m}$ after $48 \mathrm{~h}$. In our case, assuming a value of $10 \mu \mathrm{m}$ for the effective radius of fresh emitted ashes, a value of $0.6 \cdot 10^{-5} \mathrm{~m}$ was used for the conversion factor.

The above considerations allowed us to evaluate the ash mass concentration for just emitted plume. The errors on ash mass concentration are evaluated from statistical uncertainties of $\beta_{a}$, LR and $\rho$. The uncertainty on the effective radius and, therefore, on the conversion factor is a critical point, since it gives rise to a systematic error of the order of $50 \%$ on the ash mass concentration. Its contribution is not included in our results. The measurement at 12:41 GMT showed that the ash mass concentration was lower than $300 \mu \mathrm{g} \mathrm{m}^{-3}$ and $4200 \pm 2100 \mu \mathrm{g} \mathrm{m}^{-3}$ inside the plume from the BNC and the NEC, respectively. During the afternoon, from 13:50 to 14:10 GMT, the mean ash mass concentration emitted from the NEC 
was found to be $8500 \pm 4300 \mu \mathrm{g} \mathrm{m}^{-3}$. The volcanic plume from NEC had a maximum mass concentration of ash at 14:06 GMT, when the peak value of $24,000 \pm 6000 \mu \mathrm{g} \mathrm{m} \mathrm{m}^{-3}$ was observed. Finally, the measurement at 16:50 GMT showed ash mass concentration of $1000 \pm 900 \mu \mathrm{g} \mathrm{m}^{-3}$ in the plume from the BNC and of $13,000 \pm 5000 \mu \mathrm{g} \mathrm{m}^{-3}$ in the plume from the NEC.

\section{Conclusions}

Polarization lidar measurements represent a valuable tool to identify and characterize volcanic aerosol, leading to an improvement in air-traffic management capability. In this contest and for the first time, calibrated polarization lidar measurements were performed on the slope of Mount Etna, Italy, close to the summit volcanic craters, in order to investigate optical properties of just erupted volcanic plume, and to retrieve the volcanic ash mass concentration. Volcanic plumes emitted on 15 November 2010 were studied. In the morning, mean values of aerosol linear depolarization ratio lower than $1.5 \%$ were found for plume emitted from the BNC, while a mean value of (16 \pm 2$) \%$ was obtained from the NEC's emission. These results highlight the simultaneous presence of weakly depolarizing and solid volcanic aerosol. In the evening, a change in the volcanic activity took place, which caused an increase of the mean aerosol linear depolarization ratio up to $(5 \pm 2) \%$ and $(45 \pm 3) \%$ for the two plumes, respectively. Pure ash depolarization and backscattering coefficient were estimated by considering the two plumes as composed of different concentrations of depolarizing and non depolarizing aerosol. The volcanic ash mass concentration above the craters showed a moderate increase from morning to evening, with a peak value of $24,000 \pm 6000 \mu \mathrm{g} \mathrm{m}^{-3}$ at 14:06 GMT. An additional systematic uncertainty of $50 \%$ on the retrieved value of mass concentration is related with the assumption of an effective radius of $10 \mu \mathrm{m}$ for ashes. Finally, $532 \mathrm{~nm}$ lidar-ratio mean values of $46 \pm 10 \mathrm{sr}$ (corresponding to the degassing plume from BNC) and $36 \pm 5 \mathrm{sr}$ (plume from NEC) were estimated in the evening for the two well separated plumes.

\section{Acknowledgments}

The financial support by the European Community through the ACTRIS Research Infrastructure Action under the 7th Framework Programme, ACTRIS Grant Agreement n. 262254 is gratefully acknowledged.

This work is the first step for the realization of a permanent lidar station which will be realized within the ongoing project "Vamos Seguro", PO Italia-Malta, A1.2.3-62.

Authors would like to express gratitude to Prof. R. Bruzzese for helpful discussions and encouragement during our work.

\section{References}

Ansmann, A., Tesche, M., Groß, S., Freudenthaler, V., Seifert, P., Hiebsch, A. Schmidt, J., Wandinger, U., Mattis, I., Müller, D., Wiegner, M., 2010. The 16 April 2010 major volcanic ash plume over central Europe: EARLINET lidar and AERONET photometer observations at Leipzig and Munich, Germany. Geophysical Research Letters 37, L13810. http://dx.doi.org/10.1029/2010GL043809.

Ansmann, A. Tesche, M. Seifert, P. Groß, S., Freudenthaler, V., Apituley, A Wilson, K.M., Serikov, I., Linné, H., Heinold, B., Hiebsch, A., Schnell, F., Schmidt, J. Mattis, I., Wandinger, U., Wiegner, M., 2011. Ash and fine-mode particle mass profiles from EARLINET-AERONET observations over central Europe after the eruptions of the Eyjafjallajökull volcano in 2010. Journal of Geophysical Research 116, D00U02. http://dx.doi.org/10.1029/2010JD015567.

Behncke, B., Branca, S., De Beni, E., 2010. Osservazioni in area sommitale dell'Etna, 12 novembre 2010. In: INGV-Protocollo Interno $n^{\circ}$ UFVG2010/33.

Behrendt, A., Nakamura, T., 2002. Calculation of the calibration constant of polarization lidar and its dependency on atmospheric temperature. Optics Express 10 (16), 805-817.
Biele, J., Beyerle, G., Baumgarten, G., 2000. Polarization lidar: corrections of instrumental effects. Optics Express 7, 427-435. http://dx.doi.org/10.1364/ OE.7.000427.

Bissonnette, L.R., 2005. Lidar and multiple scattering. In: Weitkamp, C. (Ed.), LIDAR Range-Resolved Optical Remote Sensing of the Atmosphere. Springer, NY, USA pp. 43-103.

Bonadonna, C., Phillips, J.C., 2003. Sedimentation from strong volcanic plumes. Journal of Geophysical Research 108 (B7), 2340. http://dx.doi.org/10.1029/ 2002JB002034.

Branca, S., Del Carlo, P., 2005. Types of eruptions of Etna volcano AD 1670-2003: implications for short-term eruptive behavior. Bulletin of Volcanology 67, 732-742.

Chazette, P., David, C., Lefrère, J., Godin, S., Pelon, J., Mégie, G., 1995. Comparative lidar study of the optical, geometrical, and dynamical properties of stratospheric post-volcanic aerosols, following the eruptions of El Chichon and Mount Pinatubo. Journal of Geophysical Research 100 (D11), 23,195-23,207. http://dx.doi.org/10.1029/95JD02268.

Chester, D.K., Duncan, A.M., Guest, J.E., Kilburn, C.R.J., 1985. Mount Etna, Anatomy of a Volcano. Stanford University Press, Stanford, California.

Di Girolamo, P., Gagliardi, R.V., Pappalardo, G., Spinelli, N., Velotta, R., Berardi, V., 1995. Two wavelength lidar analysis of stratospheric aerosol size distribution. Journal of Aerosol Science 26 (6), 989-1001.

Di Girolamo, P., Pappalardo, G., Spinelli, N., Berardi, V., Velotta, R., 1996. Lidar observations of the stratospheric aerosol layer over southern Italy in the period 1991-1995. Journal of Geophysical Research - Atmosphere 101 (D13), 1876518773. http://dx.doi.org/10.1029/96JD01172.

Draxler, R.R., Rolph, G.D., 2012. HYSPLIT (HYbrid Single-Particle Lagrangian Integrated Trajectory) Model Access via NOAA ARL READY Website. NOAA Air Resources Laboratory, Silver Spring, MD. http://ready.arl.noaa.gov/HYSPLIT.php.

Edner, H. Ragnarson, P. Svanberg S., Wallinder, E, Ferrara, R, Cioni, R, Raco, B. Taddeucci, G., 1994. Total fluxes of sulfur dioxide from the Italian volcanoes Etna, Stromboli, and Vulcano measured by differential absorption lidar and passive differential optical absorption spectroscopy. Journal of Geophysical Research 99 (D9), 18, 827-18,838. http://dx.doi.org/10.1029/94JD01515.

Fernald, F.G., 1984. Analysis of atmospheric lidar observations: some comments. Applied Optics 23, 652-653. http://dx.doi.org/10.1364/A0.23.000652.

Fiorani, L., Colao, F., Palucci, A., 2009. Measurement of Mount Etna plume by $\mathrm{CO}_{2}-$ laser-based lidar. Optics Letters 34 (6), 800-802. http://dx.doi.org/10.1364/ OL.34.000800

Freudenthaler, V., Esselborn, M., Wiegner, M., Heese, B., Tesche, M., Ansmann, A., Müller, D., Althausen, D., Wirth, M., Fix, A., Ehret, G., Knippertz, P., Toledano, C., Gasteiger, J., Garhammer, M., Seefeldner, M., 2009. Depolarization ratio profiling at several wavelengths in pure Saharan dust during SAMUM 2006. Tellus 61B, 165-179. http://dx.doi.org/10.1111/j.1600-0889.2008.00396.x.

Gasteiger, J., Groß, S., Freudenthaler, V., Wiegner, M., 2011. Volcanic ash from Iceland over Munich: mass concentration retrieved from ground-based remote sensing measurements. Atmospheric Chemistry and Physics 11, 2209-2223. http://dx.doi.org/10.5194/acp-11-2209-2011.

Gro $\beta$, S., Freudenthaler, V., Wiegner, M., Gasteiger, J., Gei $\beta$, A., Schnell, F., 2012. Dualwavelength linear depolarization ratio of volcanic aerosols: lidar measurements of the Eyjafjallajökull plume over Maisach, Germany. Atmospheric Environment 48, 85-96. http://dx.doi.org/10.1016/j.atmosenv.2011.06.017.

Klett, J.D., 1985. Lidar inversion with variable backscatter/extinction ratios. Applied Optics 24, 1638-1643. http://dx.doi.org/10.1364/AO.24.001638.

Langford, A.O., O'Leary, T.., Proffitt, M.H., Hitchman, M.H., 1995. Transport of the Pinatubo volcanic aerosol to a northern midlatitude site. Journal of Geophysical Research 100 (D5), 9007-9016. http://dx.doi.org/10.1029/95JD00384.

Marenco, F., Hogan, R.J., 2011. Determining the contribution of volcanic ash and boundary layer aerosol in backscatter lidar returns: a three component atmosphere approach. Journal of Geophysical Research 116, D00U06. http:// dx.doi.org/10.1029/2010JD015415.

Mather, T.A., Pyle, D.M., Oppenheimer, C., 2003. Tropospheric volcanic aerosol. In: Robock, A., Oppenheimer, C. (Eds.), Volcanism and the Earth's Atmosphere. Geophysical Monograph Series, vol. 139. AGU, Washington, pp. 189-212.

Miffre, A., David, G., Thomas, B., Rairoux, P., 2011. Atmospheric non-spherical particles optical properties from UV-polarization Lidar and scattering matrix. Geophysical Research Letters 38, L16804. http://dx.doi.org/10.1029/2011GL048310.

Mona, L., Amodeo, A., Pandolfi, M., Pappalardo, G., 2006. Saharan dust intrusions in the Mediterranean area: three years of Raman lidar measurements. Journal of Geophysical Research 111, D16203. http://dx.doi.org/10.1029/2005JD006569.

Mona, L., Amodeo, A., D’Amico, G., Giunta, A., Madonna, F., Pappalardo, G., 2012. Multi-wavelength Raman lidar observations of the Eyjafjallajökull volcanic cloud over Potenza, southern Italy. Atmospheric Chemistry and Physics 12 , 2229-2244. http://dx.doi.org/10.5194/acp-12-2229-2012.

Oppenheimer, C., 2003. Volcanic degassing. In: Turekian, K.K., Holland, H.D. (Eds.), Treatise on Geochemistry, vol. 3. Elsevier Ltd, Amsterdam, Netherlands.

Papayannis, A., Amiridis, V., Mona, L., Tsaknakis, G., Balis, D., Bösenberg, J., Chaikovski, A., De Tomasi, F., Grigorov, I., Mattis, I., Mitev, V., Müller, D., Nickovic, S., Pérez, C., Pietruczuk, A., Pisani, G., Ravetta, F., Rizi, V., Sicard, M., Trickl, T., Wiegner, M., Gerding, M., Mamouri, R.E., D’Amico, G., Pappalardo, G., 2008. Systematic lidar observations of Saharan dust over Europe in the frame of EARLINET (2000-2002). Journal of Geophysical Research 113, D10204. http:// dx.doi.org/10.1029/2007JD009028.

Pappalardo, G., Amodeo, A., Mona, L., Pandolfi, M., Pergola, N., Cuomo, V., 2004. Raman lidar observations of aerosol emitted during the 2002 Etna eruption. 
Geophysical Research Letters 31 (L05120), 4. http://dx.doi.org/10.1029/ 2003GL019073.

Rocadenbosch, F., Reba, M.N.Md., Sicard, M., Comerón, A., 2010. Practical analytical backscatter error bars for elastic one-component lidar inversion algorithm. Applied Optics 49 (17), 3380-3393.

Rolph, G.D., 2012. Real-time Environmental Applications and Display sYstem (READY) Website. NOAA Air Resources Laboratory, Silver Spring, MD. http:// ready.arl.noaa.gov.

Sassen, K., 2005. Polarization lidar. In: Weitkamp, C. (Ed.), LIDAR Range-Resolved Optical Remote Sensing of the Atmosphere. Springer, NY, USA, pp. 19-42.

Sassen, K., Zhu, J., Webley, P., Dean, K., Cobb, P., 2007. Volcanic ash plume identification using polarization lidar: Augustine eruption, Alaska. Geophysical Research Letters 34 (L08803), 4. http://dx.doi.org/10.1029/2006GL027237.

Schumann, U., Weinzierl, B., Reitebuch, O., Schlager, H., Minikin, A., Forster, C., Baumann, R., Sailer, T., Graf, K., Mannstein, H., Voigt, C., Rahm, S., Simmet, R., Scheibe, M., Lichtenstern, M., Stock, P., Rüba, H., Schäuble, D., Tafferner, A., Rautenhaus, M., Gerz, T., Ziereis, H., Krautstrunk, M., Mallaun, C., Gayet, J.F., Lieke, K., Kandler, K., Ebert, M., Weinbruch, S., Stohl, A., Gasteiger, J., Groß, S., Freudenthaler, V., Wiegner, M., Ansmann, A., Tesche, M., Olafsson, H., Sturm, K., 2011. Airborne observations of the Eyjafjalla volcano ash cloud over Europe during air space closure in April and May 2010. Atmospheric Chemistry and Physics 11, 2245-2279. http://dx.doi.org/10.5194/acp-11-2245-2011.

Scollo, S., Coltelli, M., Prodi, F., Folegani, M., Natali, S., 2005. Terminal settling velocity measurements of volcanic ash during the 2002-2003 Etna eruption by an X-band microwave rain gauge disdrometer. Geophysical Research Letters 32 , L10302. http://dx.doi.org/10.1029/2004GL022100.

Sicard, M., Rocadenbosch, F., Reba, M.N.M., Comeron, A., Tomas, S., GarciaVızcaino, D., Batet, O., Barrios, R., Kumar, D., Baldasano, J.M., 2011. Seasonal variability of aerosol optical properties observed by means of a Raman lidar at an EARLINET site over Northeastern Spain. Atmospheric Chemistry and Physics 11, 175-190. http://dx.doi.org/10.5194/acp-11-175-2011.

Tesche, M., Ansmann, A., Müller, D., Althausen, D., Engelmann, R., Freudenthaler, V. Groß, S., 2009. Separation of dust and smoke profiles over Cape Verde by using multiwavelength Raman and polarization lidars during SAMUM 2008. Journal of Geophysical Research 114, D13202. http://dx.doi.org/10.1029/2009JD011862.

Wang, X., Boselli, A., D’Avino, L., Pisani, G., Spinelli, N., Amodeo, A., Chaikovsky, A. Wiegner, M., Nickovic, S., Papayannis, A., Perrone, M.R., Rizi, V., Sauvage, L., Stohl, A., 2008a. Volcanic dust characterization by EARLINET during Etna's eruptions in 2001-2002. Atmospheric Environment 42 (5), 893-905. http:// dx.doi.org/10.1016/j.atmosenv.2007.10.020.

Wang, X., Lu, X., Nasti, L., Zhao, Y., 2008b. Lidar measurements of aerosol depolarization ratio. Chemical Engineering Transaction 16, 53-59.

Wiegner, M., Gasteiger, J., Groß, S., Schnell, F., Freudenthaler, V., Forkel, R. Characterization of the Eyjafjallajökull ash-plume: potential of lidar remote sensing, Physics and Chemistry of the Earth, in press.

Winker, D.M., Osborn, M.T., 1992. Preliminary analysis of observations of the Pinatubo volcanic plume with a polarization-sensitive lidar. Geophysical Research Letters 19 (2), 171-174. http://dx.doi.org/10.1029/91GL02866. 